\title{
Evaluation of the Effect of TiC Precipitates on the Hydrogen Trapping Capacity of Fe-C-Ti Alloys
}

\author{
T. Depover ${ }^{1, a}$, E. Van den Eeckhout ${ }^{1, b}$, E. Wallaert ${ }^{1, c}$, Z. Zermout ${ }^{2, d}$ \\ and K. Verbeken ${ }^{1, \mathrm{e}}$
}

${ }^{1}$ Department of Materials Science and Engineering, Ghent University (UGent), Technologiepark 903, B-9052 Ghent, Belgium

\author{
${ }^{2}$ ArcelorMittal Global R\&D Gent, J.F.Kennedylaan 3, B-9060 Zelzate, Belgium \\ atom.depover@ugent.be, bemilie.vandeneeckhout@ugent.be, celien.wallaert@ugent.be, \\ dzinedine.zermout@arcelormittal.com, ${ }^{\mathrm{d}}$ kim.verbeken@ugent.be
}

Keywords: trapping capacity, TiC, hydrogen charging capacity, TDS

\begin{abstract}
The present work evaluates the hydrogen trapping behavior of different laboratory cast generic Fe$\mathrm{C}$-Ti martensitic alloys. Titanium carbides were precipitated in the materials by well-designed heat treatments. A quenched and tempered martensitic matrix with final strength above $1000 \mathrm{MPa}$ was aimed for and verified by means of hardness measurements. Tempering allowed generating precipitates with different characteristics in terms of coherency, size and distribution due to the secondary hardening effect, as was evaluated by transmission electron microscopy. The hydrogen trapping capacity of the TiC precipitates was investigated by thermal desorption spectroscopy, while melt extraction was performed to determine the amount of hydrogen present after cathodic hydrogen charging. Generally, it could be concluded that the incoherent particles in the quenched material were not able to trap hydrogen, whereas the quenched and tempered material trapped hydrogen at the interface of small probably coherent $\mathrm{TiC}$.
\end{abstract}

\section{Introduction}

Recently, many industrial developments focus on steels with a tensile strength above $1000 \mathrm{MPa}$ in order to fulfill the requirements desired by for instance the automotive industry to reduce for example emissions. Moreover, lowering the weight of vehicles is a crucial subject in order to reduce the polluting emissions. High strength steels are good candidates to meet these requests, but unfortunately these grades are more sensitive to hydrogen embrittlement (HE). Hydrogen embrittles materials and gives rise to an unpredictable failure, which can lead to catastrophic consequences. Carbides are often mentioned to have a positive effect in terms of HE, as these precipitates are able to trap hydrogen strongly, preventing it from reaching more damaging reversible trapping sites where they can initiate fracture. Nevertheless, a fundamental understanding of the role of carbides on HE susceptibility is lacking. Although, it is generally assumed that inhibiting diffusible hydrogen by introducing nano-carbides as hydrogen trap is one of the approaches to reduce the susceptibility to HE.

Pressouyre et al. [1] investigated by means of the hydrogen permeation technique the behavior of hydrogen with $\mathrm{TiC}$ and determined an activation energy $\left(\mathrm{E}_{\mathrm{a}}\right)$ about $95 \mathrm{~kJ} / \mathrm{mol}$, while Lee and Lee [2] studied the interaction of hydrogen with the matrix/precipitate interface of TiC inclusions in iron by thermal desorption spectroscopy (TDS) and obtained an $\mathrm{E}_{\mathrm{a}}$ of $86.9 \mathrm{~kJ} / \mathrm{mol}$. Wei et al. [3] determined the $\mathrm{E}_{\mathrm{a}}$ for hydrogen from the incoherent $\mathrm{TiC}$ particles in a $0.05 \mathrm{C}-0.22 \mathrm{Ti}-2.0 \mathrm{Ni}$ steel to be $85.7 \mathrm{~kJ} / \mathrm{mol}$, while in another steel $(0.42 \mathrm{C}-0.30 \mathrm{Ti})$ with larger incoherent $\mathrm{TiC}$ the $\mathrm{E}_{\mathrm{a}}$ was about $116 \mathrm{~kJ} / \mathrm{mol}$, whereas the coherent precipitates showed an $\mathrm{E}_{\mathrm{a}}$ between 46 and $59 \mathrm{~kJ} / \mathrm{mol}$. Consequently, it could be assumed that the degree of coherence plays a crucial role. Pressouyre et al. [1] reported that coherent $\mathrm{TiC}$ are less effective as trap site compared to incoherent particles and that the $\mathrm{E}_{\mathrm{a}}$ as trap increases with precipitate size. Similar conclusions were drawn by Lee et al. [4]. 
Wei et al. [5] found that the amount of trapped hydrogen could be correlated to the size of the precipitate, suggesting that hydrogen is trapped at the $\mathrm{TiC} /$ matrix interface. This was later confirmed by the work of Takahashi et al. [6], who performed a direct observation of deuterium atoms trapped along the broad surfaces at $\mathrm{TiC}$ precipitates by using atom probe tomography.

The aim of this work is to evaluate the trapping capacity of TiC precipitates in, on the one hand, a quenched material containing incoherent particles and, on the other hand, a quenched and tempered sample where many probably coherent $\mathrm{TiC}$ of about 3-5 $\mathrm{nm}$ are introduced.

\section{Experimental Procedure}

Three alloys with different carbon contents and stoichiometric amount of titanium were cast and processed at ArcelorMittal Global R\&D Gent Center. The chemical compositions of the alloys are presented in Table 1.

Table 1: Chemical compositions of the Fe-C-Ti materials.

\begin{tabular}{|l|l|l|l|}
\hline Alloy & wt.\% C & wt.\% Ti & Other elements \\
\hline A & 0.099 & 0.38 & Al: $200-300$ wt. ppm \\
\cline { 1 - 3 } B & 0.202 & 0.74 & \\
\cline { 1 - 3 } C & 0.313 & 1.34 & Other elements traces \\
\hline
\end{tabular}

The materials were hot and cold rolled till $1 \mathrm{~mm}$ and further austenitized at $1250^{\circ} \mathrm{C}$ for one hour followed by water quenching. A tempering thermal treatment, as summarized in Fig.1, was performed in air in order to determine the optimum temperature at which secondary hardening, due to $\mathrm{TiC}$ precipitation, occurs.

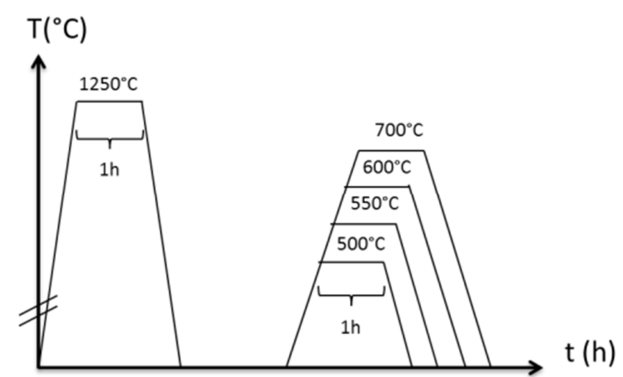

Figure 1: Schematized heat treatment used to detect secondary hardening peak.

In order study the hydrogen interaction with the alloys, several equipments belonging to ArcelorMittal Global R\&D Gent Center were used. To determine the hydrogen content, a melt extraction technique was used. The experimental details can be found elsewhere [7, 8]. Electrochemical charging was done for one hour using a $1 \mathrm{~g} / \mathrm{L}$ thiourea $0.5 \mathrm{M} \mathrm{H}_{2} \mathrm{SO}_{4}$ based solution at a constant current density of $0.8 \mathrm{~mA} / \mathrm{cm}^{2}$. TDS analysis was performed as well in order to identify the hydrogen trapping sites and their $\mathrm{E}_{\mathrm{a}}$. The samples were charged identically and three different heating rates $\left(200^{\circ} \mathrm{C} / \mathrm{h}, 600^{\circ} \mathrm{C} / \mathrm{h}\right.$ and $\left.1200^{\circ} \mathrm{C} / \mathrm{h}\right)$ were used. The amount of released gaseous $\mathrm{H}_{2}$ at certain temperatures was recorded. In order to determine the $\mathrm{E}_{\mathrm{a}}$ of hydrogen traps related to the peaks observed in the TDS spectra, the method based on the work of Lee et al. [9, 10, 11] was used. Equation (1) is a simplification of the original formula of Kissinger [12]:

$$
\left(\mathrm{d}\left(\ln \left(\Phi /\left(\mathrm{T}_{\max }^{2}\right)\right)\right) /\left(\mathrm{d}\left(1 / \mathrm{T}_{\max }\right)\right)=-\mathrm{E}_{\mathrm{a}} / \mathrm{R}\right.
$$

Where $\Phi$ is the heating rate $(\mathrm{K} / \mathrm{min}), \mathrm{T}_{\max }(\mathrm{K})$ the TDS maximum peak temperature, $\mathrm{E}_{\mathrm{a}}(\mathrm{J} / \mathrm{mol})$ the activation energy for the specific $\mathrm{H}$ trap associated with $\mathrm{T}_{\max }$ and $\mathrm{R}\left(\mathrm{JK}^{-1} \mathrm{~mol}^{-1}\right)$ the universal gas constant. After determining the corresponding peak temperatures for a trap, plotting $\left.\ln \left(\Phi / \mathrm{T}_{\max }{ }^{2}\right)\right)$ vs. $\left(1 / T_{\max }\right)$ allows to obtain the $E_{a}$ corresponding to that specific trap. 


\section{Materials Characterization}

In this work, the focus will be put on alloy $\mathrm{C}$ and the optical microstructures of the quenched and quenched and tempered $\left(600^{\circ} \mathrm{C}\right)$ condition are presented in Fig. 2. Further details can be found elsewhere [7]. Quenching resulted in a fully martensitic microstructure and the black dots presented in the matrix are most likely incoherent TiC carbides.
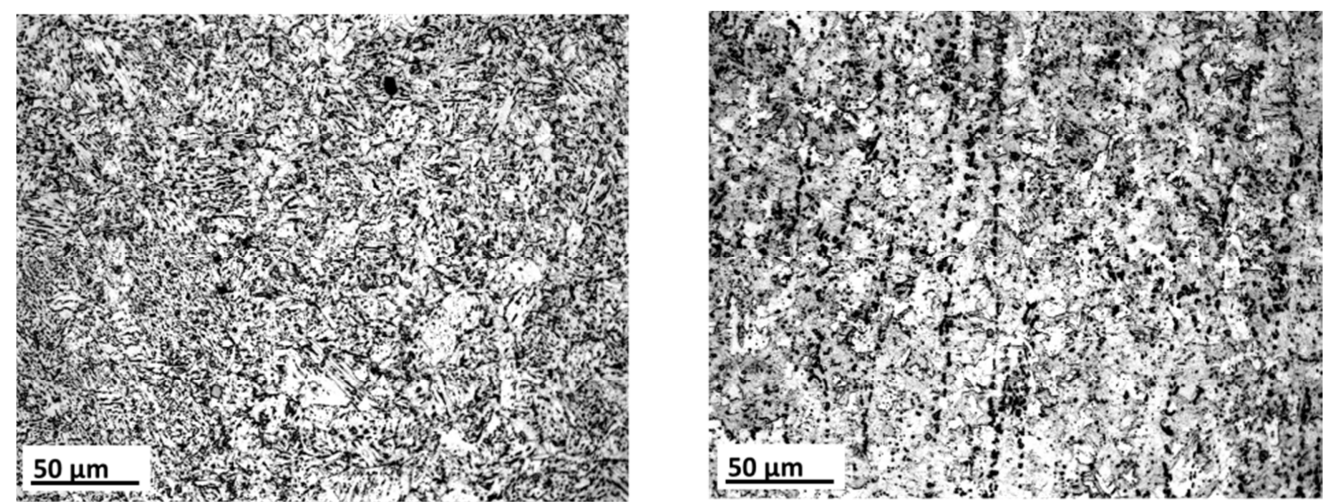

Figure 2: Optical microscope images of alloy $\mathrm{C}$ in the quenched (left) and quenched and tempered at $600^{\circ} \mathrm{C}$ (right) condition.

\section{Results and Discussion}

The effect of tempering temperature on the hardness level is denoted in Fig. 3 (left), where the secondary hardening behavior can be clearly observed with a maximum hardness around $600^{\circ} \mathrm{C}$. The as quenched samples' hardness is rather similar at about $260 \mathrm{HV}$. This hardness is mainly determined by the amount of interstitial free carbon. The amount of free carbon as a function of the temperature can be calculated using a classical solubility product equation [13]. The results are represented in Fig. 3 (right). It can be concluded that for all the alloys, approximately $450 \mathrm{wt}$. ppm of carbon can be kept in solid solution at $1250^{\circ} \mathrm{C}$ for stoichiometric contents of $\mathrm{Ti}$ and $\mathrm{C}$. Besides, the increasing variance between the materials when tempered can be attributed to the presence of a variable amount of large carbides from the processing which are able to pin the grain boundaries and hence impede grain growth, although further TEM analysis is suggested to demonstrate this.
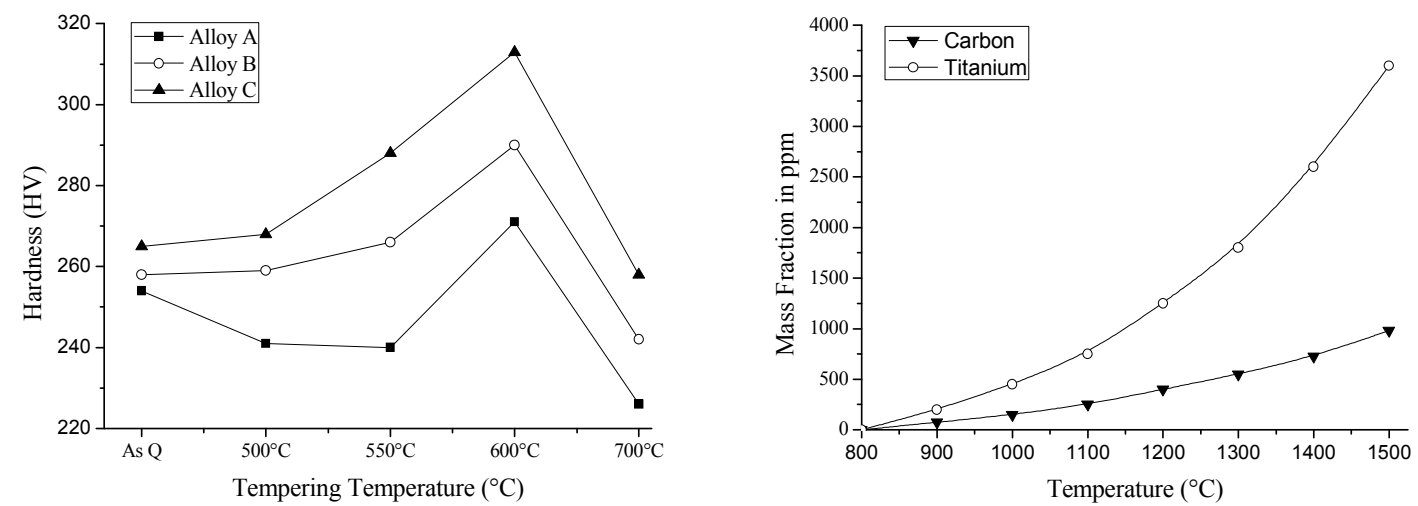

Figure 3: Effect of tempering temperature on Vickers Hardness, As Q - as quenched (left), mass fraction of $\mathrm{Ti}$ and $\mathrm{C}(\mathrm{ppm})$ vs. temperature $\left({ }^{\circ} \mathrm{C}\right)$ that can be kept in solid solution at each temperature for stoichiometric total contents of $\mathrm{C}$ and $\mathrm{Ti}$ (right).

A thorough microstructural study by means of TEM was further performed on alloy $\mathrm{C}$ in both the as quenched and the quenched and tempered condition, since the highest hardness level was achieved for this grade when tempered at $600^{\circ} \mathrm{C}$ for one hour. At higher temperatures the hardness decreases due to phenomena such as recovery, recrystallization, grain growth and coarsening of the carbides. A TEM image of the as quenched sample is presented in Fig. 4 (left), where the laths of the martensitic structure are clearly visible. Moreover, large carbides are found, which are most probably incoherent due to their size and formed before quenching the materials (Fig. 4 centre). The 
average diameter of the carbides is about $366 \mathrm{~nm}$. An Energy Dispersive X-ray (EDX) spectrum was taken in order to confirm the precipitates are indeed TiC [7]. A dark field TEM image of the sample which was tempered is shown in Fig. 4 (right) and further discussed elsewhere [7]. The numerous white spots could be assigned to small probably coherent $\mathrm{TiC}$ formed during tempering. EDX measurements were taken [7] and it could be concluded that TiC of about 2-5 nm are formed during the tempering process. This was also observed by Wei and Tsuzaki [5].
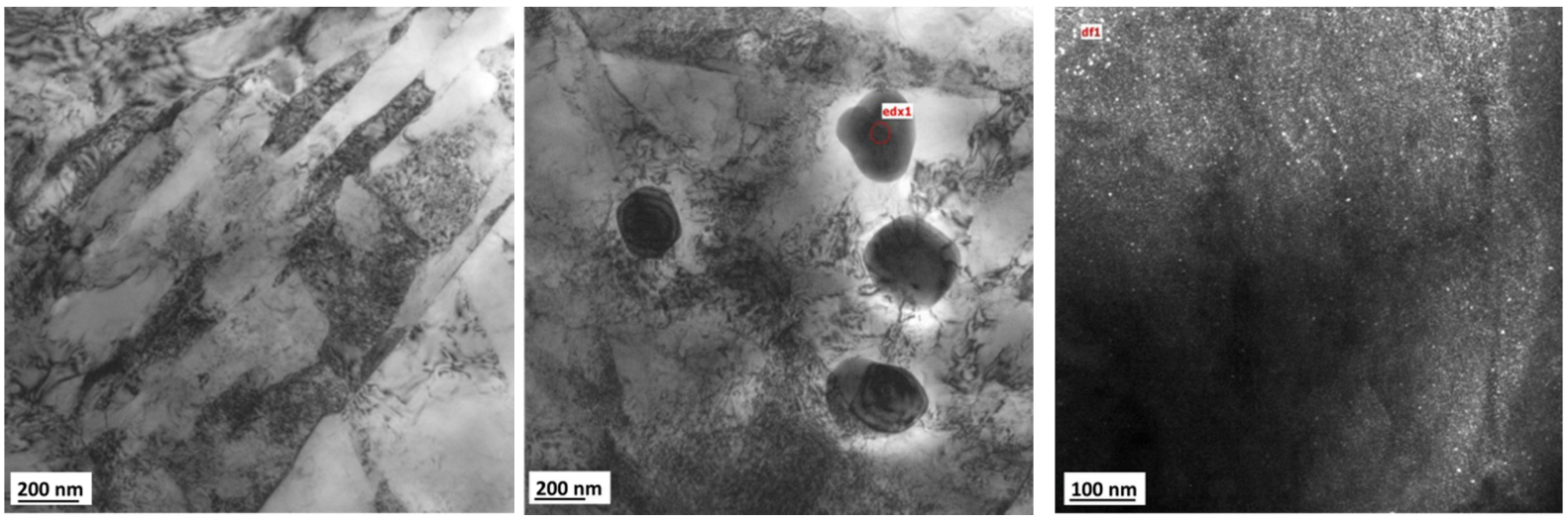

Figure 4: TEM bright field images of the quenched sample of alloy $\mathrm{C}$ (left) and of the TiC (centre), a dark field TEM image of the quenched and tempered material $\left(600^{\circ} \mathrm{C}\right)$ (right)

The results of the hydrogen melt extraction (charged or uncharged) are presented in Fig. 5.

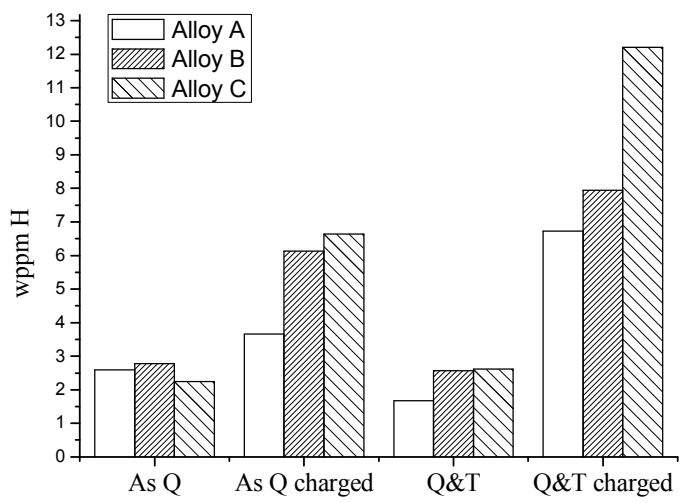

Figure 5: Melt extraction results for the three alloys as quenched (As Q) or quenched and tempered $(\mathrm{Q} \& \mathrm{~T})\left(600^{\circ} \mathrm{C}\right)$ in uncharged and hydrogen charged condition.

In a martensitic structure, many hydrogen traps such as grain boundaries, dislocations, internal stress regions or free carbon are present. Since an equal amount of carbon is dissolved from the carbides during austenitizing for the three grades, a higher amount of incoherent carbides in the matrix is present when the initial carbon content rises. Around these carbides, lattice distortions are present which can be filled with hydrogen. The hydrogen content present in the uncharged samples is trapped in the material during its processing. Charging of the as quenched samples was effective and a higher amount of carbon lead to a considerable hydrogen uptake. Grain boundaries and high stress regions around the incoherent carbides are filled with hydrogen during cathodic charging.

Chan [14] reported that the hydrogen content was drastically reduced when a martensitic structure was tempered and related this with a decrease in dislocation density during tempering. For the alloys of this study (cf. Fig. 5), although the dislocation density is expected to decrease with the tempering, the charged quenched and tempered samples trapped more hydrogen compared to the as quenched ones. This is probably due to the presence of small coherent carbides which are formed during secondary hardening and which can trap hydrogen at their interface with the matrix. The incoherent $\mathrm{TiC}$, present in the as quenched condition, were not able to trap hydrogen electrochemically. Similar observations were seen by Wei and Tsuzaki [5] and Escobar [8]. 
A thorough hydrogen related characterization by TDS was done on alloy $\mathrm{C}$ for both the as quenched and quenched and tempered condition. The TDS spectra at a heating rate of $600^{\circ} \mathrm{C} / \mathrm{h}$ are respectively shown in Fig. 6 (left) and (right).
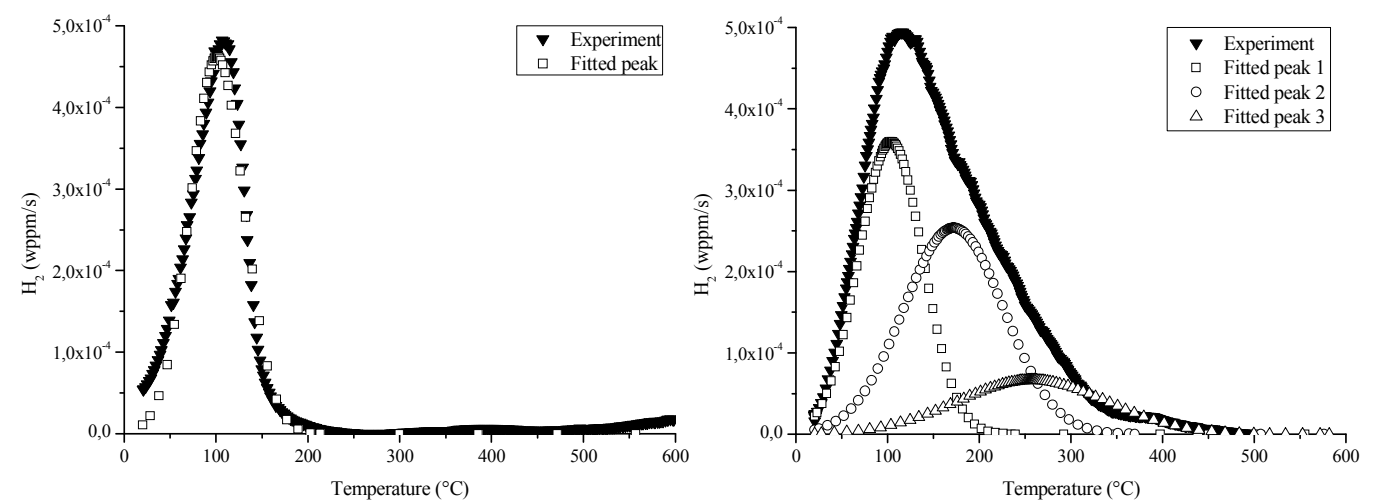

Figure 6: TDS spectrum of alloy $\mathrm{C}$ in as quenched (left) and quenched and tempered (right) condition - at a heating rate of $600^{\circ} \mathrm{C} / \mathrm{h}$.

No high temperature peak was observed, indicating that no hydrogen was irreversibly trapped up to $600^{\circ} \mathrm{C}$. Wei et al. [3] observed by TDS that hydrogen trapped at TiC particles can desorb at about $150{ }^{\circ} \mathrm{C}$, corresponding to an $\mathrm{E}_{\mathrm{a}}$ of approximately $58 \mathrm{~kJ} / \mathrm{mol}$. This $\mathrm{E}_{\mathrm{a}}$ is on the border between reversible and irreversible traps. Nevertheless, at room temperature, the incoherent TiC do not trap hydrogen during cathodic charging because the energy barrier is too high [5]. Gaseous charging at high temperature is required as described by Escobar et al. [8]. The $\mathrm{E}_{\mathrm{a}}$ for the peaks, calculated as described previously, are summarized in Table 2.

Table 2: $\mathrm{E}_{\mathrm{a}}$ (with standard deviation out of three measurements) of the deconvoluted peaks of alloy $\mathrm{C}$ in the as $\mathrm{Q}$ and $\mathrm{Q} \& \mathrm{~T}$ condition,

\begin{tabular}{|c|c|c|}
\hline Activation energy (kJ/mol) & As quenched & Quenched and tempered \\
\hline Peak 1 & $33 \pm 2$ & $39 \pm 1$ \\
\hline Peak 2 & - & $29 \pm 3$ \\
\hline Peak 3 & - & $32 \pm 4$ \\
\hline
\end{tabular}

The TDS spectrum of the quenched sample is deconvoluted into one peak corresponding to an $\mathrm{E}_{\mathrm{a}}$ of $33 \mathrm{~kJ} / \mathrm{mol}$, whereas the spectrum of the tempered sample can be deconvoluted into three peaks corresponding to 39,29 and $32 \mathrm{~kJ} / \mathrm{mol}$. The first hydrogen desorption peak of both samples can be attributed to hydrogen trapped at the grain boundaries. The latter two peaks of the tempered sample have similar $\mathrm{E}_{\mathrm{a}}$ 's and are assumed to be produced by the hydrogen trapped at the interface between the matrix and the coherent TiC carbides. An in-depth TEM investigation concerning the coherency is suggested to confirm this.

Pressouyre and Bernstein [1] published that the TiC precipitates trap hydrogen more reversible when its coherence with the matrix is increased, leading to a lower $E_{a}$. The lower $E_{a}$ compared to the results of Wei et al. [3, 5] can probably be related to the difference in coherency of the precipitates. Similar findings were obtained by E. Wallaert et al. [15] where a TDS evaluation of the hydrogen trapping of $\mathrm{NbC}$ precipitates was performed.

\section{Conclusions}

Three generic Fe-C-Ti alloys were cast and processed in order to obtain a high strength/hardness level and evaluate the effect of hydrogen trapping of TiC precipitates by TDS and melt extraction. Quenching and tempering was executed in order to fulfill the hardness requirements. The secondary hardening effect was at its optimum when the materials got tempered at $600^{\circ} \mathrm{C}$. The precipitation of small probably coherent $\mathrm{TiC}$ was responsible for this behavior as demonstrated by a comparison of TEM analysis for both the quenched and the tempered materials. Incoherent large carbides of about 
$350 \mathrm{~nm}$ could be detected in the quenched material, whereas small $\mathrm{TiC}$ precipitates of approximately $2-5 \mathrm{~nm}$ were identified in the tempered sample.

A hydrogen related characterization was executed in terms of melt extraction, where it could be observed that the quenched and tempered material was able to trap 3-6 wppm of hydrogen more than the quenched sample. This can also be correlated with the presence of small coherent TiC in the tempered grade. Furthermore, TDS analysis confirmed the obtained tendencies, since the tempered sample contained two extra hydrogen peaks compared to the quenched one, which could be attributed to hydrogen trapped in the interface between the small coherent precipitates and the matrix.

\section{Acknowledgements}

The authors wish to thank the Special Research Fund (BOF), UGent (BOF10/ZAP/121) and the Agency for Innovation by Science and Technology in Flanders (IWT) for support (Project nr SB111205). The authors also acknowledge the technicians and staff working at the hydrogen laboratory at OCAS (ArcelorMittal R\&D Gent) and the technical staff from the Department Materials Science and Engineering, UGent, for their help and guidance.

\section{References}

[1] G.M. Pressouyre, I.M. Bernstein, Metall Trans 9A (1978) 1571-1580.

[2] H.G. Lee, J.Y. Lee, H trapping by TiC particles in Fe, Acta Metall 32 (1984) 131-136.

[3] F. Wei, T. Hara and K. Tsuzaki, Metall. Mater. Trans. B, 35B (2004) 587-597.

[4] S.M. Lee, J.Y. Lee, Acta Metall 35 (1987) 2695-2700.

[5] F. Wei and K. Tsuzaki, Metal Mater Trans A, 37A (2006) 331-353.

[6] J. Takahashi, K. Kawakami, Y. Kobayashi, T. Tarui, Scripta Mater 63 (2010) 261-264.

[7] T. Depover, E. Van den Eeckhout, E. Wallaert, Z. Zermout, K. Verbeken, in progress.

[8] D. Escobar, E. Wallaert, L. Duprez, A. Atrens, and K. Verbeken, Met. Mater. Int., 19 No. 4 (2013) 741-748.

[9] S. Lee and J. Lee, Metallurgical Transactions A, 17A (1986) 181-187.

[10] J. Lee and S. Lee, Surface and Coatings Technology, 28 (1986) 301-314.

[11] J. Lee and J. Lee, Metal Science, 17 (1983) 426-432.

[12] H. Kissinger, Analytical Chemistry, 29, (1957) 1702-1706.

[13] A. A. Gorni, Steel Forming and Heat Treating Handbook, São Vicente, Brazil, 2002.

[14] S. Chan, J Chin Inst Eng, 22 (1999) 43-53.

[15] E. Wallaert, T. Depover, M. Arafin and K. Verbeken, in progress. 